\title{
Phylogenetic Analysis of the Genera Cellulomonas, Promicromonospora, and Jonesia and Proposal To Exclude the Genus Jonesia from the Family Cellulomonadaceae
}

\author{
FRED A. RAINEY, NORBERT WEISS, AND ERKO STACKEBRANDT** \\ DSM-Deutsche Sammlung von Mikroorganismen und Zellkulturen GmbH, \\ 38124 Braunschweig, Germany
}

\begin{abstract}
The 16S rRNA gene sequences of eight Cellulomonas species, two Promicromonospora species, and Jonesia denitrificans were determined, and these sequences were compared with the sequences of about 50 representatives of the Arthrobacter line of descent in the order Actinomycetales. We found that in spite of its current assignment to the family Cellulomonadaceae, J. denitrificans branches outside the radiation of this taxon and cannot be considered a member of it. The two Promicromonospora species do not cluster separately from Cellulomonas species and are more closely related to Cellulomonas species than to each other.
\end{abstract}

The family Cellulomonadaceae currently contains the following four genera, which have been deemed to be phylogenetically related on the basis of partial $16 \mathrm{~S}$ rRNA sequence data: Cellulomonas, Oerskovia, Promicromonospora, and Jonesia (18, $21,22,24-27)$. One of these genera, the genus Jonesia, is the most dissimilar genus in terms of chemotaxonomic properties, as exemplified by a DNA $\mathrm{G}+\mathrm{C}$ content that is about $15 \mathrm{~mol} \%$ lower than the $\mathrm{G}+\mathrm{C}$ contents found in the other members of the family and by the presence of fully saturated isoprenologs (MK-9); the other members of the family possess hydrogenated menaquinones of the MK-9 $\left(\mathrm{H}_{4}\right)$ type (18). The placement of the genus Jonesia in the family Cellulomonadaceae was not unambiguous $(26,27)$ because the branching point of the only species, Jonesia denitrificans, did not fall consistently within the radiation of cellulomonads but changed according to the number and choice of reference organisms included in analyses of $16 \mathrm{~S}$ rRNA catalogs.

A second problem concerns the relatedness of the genera Cellulomonas and Oerskovia. Members of these two genera have been found to be phylogenetically intermixed (22), which has led to the transfer of Oerskovia species to the genus $\mathrm{Cel}$ lulomonas (28). On the other hand, morphological characteristics and the amino acid compositions of peptidoglycans, characteristics which have been used in the past to delineate actinomycete genera, differ in members of these two genera (5, $20,21,22)$. A taxon name does not become invalid because of a proposed taxonomic rearrangement (13), and the genus Oerskovia was included as a separate genus in the description of the family Cellulomonadaceae (27).

To provide a phylogenetically more stable basis for the genera of the family Cellulomonadaceae and to identify the position of the genera mentioned above within the radiation of the Arthrobacter branch of the order Actinomycetales, we sequenced the almost complete $16 \mathrm{~S}$ ribosomal DNAs (rDNAs) of the type strains of all validly described Cellulomonas species and compared these sequences with the homologous sequences available for other actinomycetes.

\footnotetext{
* Corresponding author. Mailing address: DSM-Deutsche Sammlung von Mikroorganismen und Zellkulturen $\mathrm{GmbH}$, Mascheroder Weg 1b, 38124 Braunschweig, Germany. Phone: 495312616352. Fax: 495312616 418. Electronic mail address: stackebrandt@venus. gbf-braunschweig.d400.de.
}

\section{MATERIALS AND METHODS}

Strains investigated. Cellulomonas biazotea DSM $20112^{\mathrm{T}}(\mathrm{T}=$ type strain , Cellulomonas cellasea DSM $20118^{\mathrm{T}}$, Cellulomonas cellulans DSM $43879^{\mathrm{T}}$, Cellulomonas fermentans DSM $3133^{\mathrm{T}}$, Cellulomonas fimi DSM $20113^{\mathrm{T}}$, Cellulomonas flavigena DSM $20109^{\mathrm{T}}$, Cellulomonas gelida DSM $20111^{\mathrm{T}}$, Cellulomonas (Oer skovia) turbata DSM $20577^{\mathrm{T}}$, Cellulomonas uda DSM $20107^{\mathrm{T}}, J$. denitrificans DSM $20603^{\mathrm{T}}$, Promicromonospora citrea DSM $43110^{\mathrm{T}}$, Promicromonospora en terophila DSM $43852^{\mathrm{T}}$, Brachybacterium faecium DSM $4810^{\mathrm{T}}$, Terrabacter tume scens DSM $20308^{\mathrm{T}}$, and Brevibacterium iodinum DSM $20626^{\mathrm{T}}$ are deposited in the DSM-German Collection of Microorganisms and Cell Cultures $\mathrm{GmbH}$. CelLulomonas, Terrabacter, and Brevibacterium, Jonesia, Promicromonospora, and Brachybacterium strains were cultivated on media 53,215, 65, and 92, as described in the DSM-Deutsche Sammlung von Mikroorganismen und Zellkulturen $\mathrm{GmbH}$ catalog of strains.

Analysis of 16S rDNA. Extraction of genomic DNA and amplification of the 16 S rDNA were carried out as described previously (16). PCR products were sequenced directly by using a Taq DyeDeoxy Terminator Cycle Sequencing Kit (Applied Biosystems) according to the manufacturer's protocol. The sequence reaction mixtures were electrophoresed by using an Applied Biosystems model 373A DNA sequencer.

Phylogenetic analysis. The 16S rDNA sequences which we determined were compared with a $16 \mathrm{~S}$ rDNA database consisting of the sequences of members of the Arthrobacter line of descent in the subphylum containing the order Actinomycetales, including sequences deposited in the Ribosomal Database Project (14) and recent releases $(1,11,12,17)$. Dissimilarity values were transformed into phylogenetic distance values that compensated for multiple substitutions at any given site in the sequence (10). Phylogenetic trees were reconstructed by additive treeing methods, such as the algorithms of De Soete (3) and Saitou and Nei (19), by using the corrected dissimilarity values. To calculate bootstrap values for 930 polymorphic sites, we analyzed 300 trees.

Peptidoglycan analysis. Preparation of cell walls and determination of peptidoglycan structure were carried out by previously described methods (20), except that thin-layer chromatography on cellulose sheets (TLC plastic sheets; Cellulose 5577; Merck, Darmstadt, Germany) was used instead of paper chromatography. Portions $(1 \mathrm{mg})$ of freeze-dried cell walls were hydrolyzed in $0.2 \mathrm{ml}$ of $4 \mathrm{~N} \mathrm{HCl}$ at $100^{\circ} \mathrm{C}$ for $16 \mathrm{~h}$ and for $45 \mathrm{~min}$ to prepare total hydrolysates and partial hydrolysates, respectively. Diamino acids in the total hydrolysates were identified by using one-dimensional chromatography with a methanol-pyridine-water-10 $\mathrm{N} \mathrm{HCl}(320: 40: 70: 10, \mathrm{vol} / \mathrm{vol} / \mathrm{vol} / \mathrm{vol})$ solvent system. Amino acids and peptides in the partial and total hydrolysates were identified by their mobilities and ninhydrin staining characteristics following two-dimensional chromatography with the system described by Schleifer and Kandler (20). The resulting fingerprints were compared with the fingerprints of known peptidoglycan structures.

Nucleotide sequence accession numbers. The $16 \mathrm{~S}$ rDNA sequences which we determined have been deposited in the EMBL database under accession numbers $\mathrm{X} 83799$ to $\mathrm{X} 83813$.

\section{RESULTS AND DISCUSSION}

The almost complete 16S rDNA sequences of the 13 strains which we investigated, which consisted of between 1,420 and 1,480 nucleotides, were aligned with other sequences available 
TABLE 1. 16S rDNA similarity values for the type strains of species belonging to the family Cellulomonadaceae and some reference species investigated in this study

\begin{tabular}{|c|c|c|c|c|c|c|c|c|c|c|c|c|c|}
\hline \multirow[b]{2}{*}{ Organism } & \multicolumn{13}{|c|}{$\%$ 16S rDNA dissimilarity with: } \\
\hline & 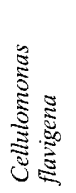 & 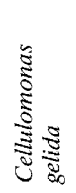 & 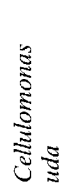 & 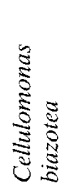 & 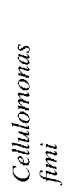 & 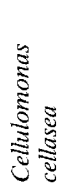 & 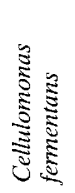 & 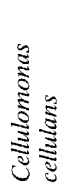 & 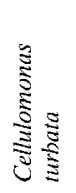 & 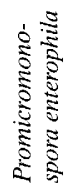 & 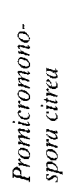 & 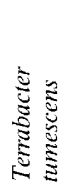 & 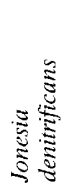 \\
\hline Cellulomonas gelida & 97.2 & & & & & & & & & & & & \\
\hline Cellulomonas uda & 96.7 & 98.8 & & & & & & & & & & & \\
\hline Cellulomonas biazotea & 96.5 & 96.4 & 96.5 & & & & & & & & & & \\
\hline Cellulomonas fimi & 96.5 & 96.4 & 96.5 & 99.7 & & & & & & & & & \\
\hline Cellulomonas cellasea & 96.2 & 96.3 & 96.2 & 98.0 & 98.0 & & & & & & & & \\
\hline Cellulomonas fermentans & 95.1 & 94.8 & 95.0 & 95.6 & 95.6 & 95.9 & & & & & & & \\
\hline Cellulomonas cellulans & 93.8 & 94.5 & 95.4 & 94.7 & 94.6 & 94.6 & 93.9 & & & & & & \\
\hline Cellulomonas turbata & 95.6 & 96.1 & 95.9 & 95.7 & 95.7 & 96.4 & 94.8 & 95.7 & & & & & \\
\hline Promicromonospora enterophila & 95.9 & 96.4 & 96.2 & 95.6 & 95.5 & 96.2 & 95.1 & 95.4 & 99.6 & & & & \\
\hline Promicromonospora citrea & 93.0 & 94.3 & 94.1 & 93.3 & 93.3 & 92.5 & 92.4 & 95.6 & 93.9 & 93.6 & & & \\
\hline Terrabacter tumescens & 92.8 & 93.8 & 93.7 & 94.2 & 94.1 & 94.4 & 94.1 & 93.9 & 94.8 & 94.6 & 92.2 & & \\
\hline Jonesia denitrificans & 90.5 & 91.2 & 91.3 & 91.5 & 91.6 & 91.8 & 90.4 & 91.6 & 91.5 & 91.2 & 91.4 & 90.9 & \\
\hline Nocardioides simplex & 88.6 & 89.1 & 89.1 & 89.0 & 89.1 & 88.6 & 88.6 & 89.6 & 88.3 & 88.6 & 89.0 & 88.5 & 86.3 \\
\hline
\end{tabular}

for a selection of species that define the arthrobacterial lineage in the order Actinomycetales. Binary similarity values were determined for members of the genera Agromyces, Arthrobacter, Brachybacterium, Brevibacterium, Clavibacter, Curtobacterium, Dermabacter, Dermatophilus, Microbacterium, Micrococcus, Rathayibacter, Renibacterium, Rothia, and Terrabacter, and a similarity matrix was generated (Table 1). The overall level of $16 \mathrm{~S} \mathrm{rDNA}$ similarity for members of this lineage was high; the $16 \mathrm{~S}$ rDNA similarity values were greater than $89 \%$ (data not shown).

Interfamily relationships. When the sequence of Nocardioides simplex was used as a reference to root the Arthrobacter lineage (4), distance matrix analyses of dissimilarity values revealed that the majority of the strains which we studied are members of the following four main clusters: the ArthrobacterMicrococcus group (12), the family Microbacteriaceae (17), the Cellulomonas group, and the Brevibacterium-Brachybacterium group (Fig. 1). Dermatophilus congolensis branches as an individual lineage. The position of the two Brevibacterium species does not agree with the position described in a recent report (1) in which the authors found that members of this genus represent a distinct actinomycete line of descent that exhibits no specific affinity to the genus Arthrobacter and its relatives. Both of the distance matrix algorithms used in this study suggested that the genus Brevibacterium, together with $J$. denitrificans, Dermabacter hominis, and Brachybacterium faecium, branches within the radiation of the Arthrobacter lineage. Low bootstrap values, however, indicated that the proposal that the Arthrobacter-Brevibacterium lineage has a common origin is not supported by the results of a statistical analysis. The phylogenetic position of $J$. denitrificans outside the radiation of the family Cellulomonadaceae is not unexpected. The same situation was found in several analyses of rRNA catalogs which were based on a significantly smaller number of sequences $(18$, 26 ). In those cases $P$. citrea also branched outside the family (18). J. denitrificans has a significantly lower DNA G+C content ( 56 to $58 \mathrm{~mol} \%$ ) than the cellulomonads ( 70 to $76 \mathrm{~mol} \%$ ). However, placement of this species outside the radiation of the Cellulomonadaceae is probably not an artifact induced by its $\mathrm{G}+\mathrm{C}$ composition because the $\mathrm{G}+\mathrm{C}$ content of the rRNA gene of this species $(56.6 \mathrm{~mol} \%)$ is within the range of values found for members of the cellulomonad lineage (54.9 to 58.3 mol\%). In several chemotaxonomic properties, such as the amino acid composition of the peptidoglycan, the presence of teichoic acids (6), the menaquinone type, and the $\mathrm{G}+\mathrm{C}$ composition of the DNA (18), J. denitrificans differs from members of the genera Cellulomonas and Promicromonospora, and these properties were not given due consideration in the original discussion concerning the allocation of the genus Jonesia to the family Cellulomonadaceae (26). Now that the phylogenetic relationship between the genus Jonesia and the CellulomonasPromicromonospora group cannot be confirmed, the rationale for keeping the genus Jonesia in this family has vanished.

On the basis of $16 \mathrm{~S}$ rDNA similarity data, the closest (albeit distant) relatives of $J$. denitrificans are Dermabacter hominis and Brachybacterium faecium. While Dermabacter hominis, a gram-positive, asporogenous, rod-shaped bacterium (9), has been isolated from human skin, Brachybacterium faecium is a pleomorphic coryneform bacterium that has been isolated from poultry deep litter (2). These two taxa are chemotaxonomically similar in that they possess meso-diaminopimelic acid in the peptidoglycan, fully unsaturated menaquinones, and fatty acid and polar lipid profiles frequently found in members of the Arthrobacter lineage (8). The presence of unsaturated menaquinones is shared with $J$. denitrificans but is not exclusive to members of the lineage. Interestingly, a loose relationship between $J$. denitrificans and Brachybacterium faecium was observed in an early numerical taxonomic analysis (7). In contrast to the previously published amino acid compositions of peptidoglycans $(2,9)$, neither Dermabacter hominis nor Brachybacterium faecium contains a directly cross-linked type A1 $\gamma$ murein, as found in other members of the genera Brevibacterium and Dermatophilus, but these organisms contain a type A4 $\gamma$ murein. While in Dermabacter hominis the peptide subunits are cross-linked by a glutamyl-asparagyl dipeptide, a diglutamyl peptide has been detected in cells of Brachybacterium faecium; in both taxa the $\alpha$-carboxyl group of D-glutamic acid is replaced by glycine. In a previous phylogenetic study (1), Dermabacter hominis occupied an individual subline of descent in the Arthrobacter lineage, exhibiting a branching point at the root of three members of the Arthrobacter group. Even though the recent increase in the number of sequences of 


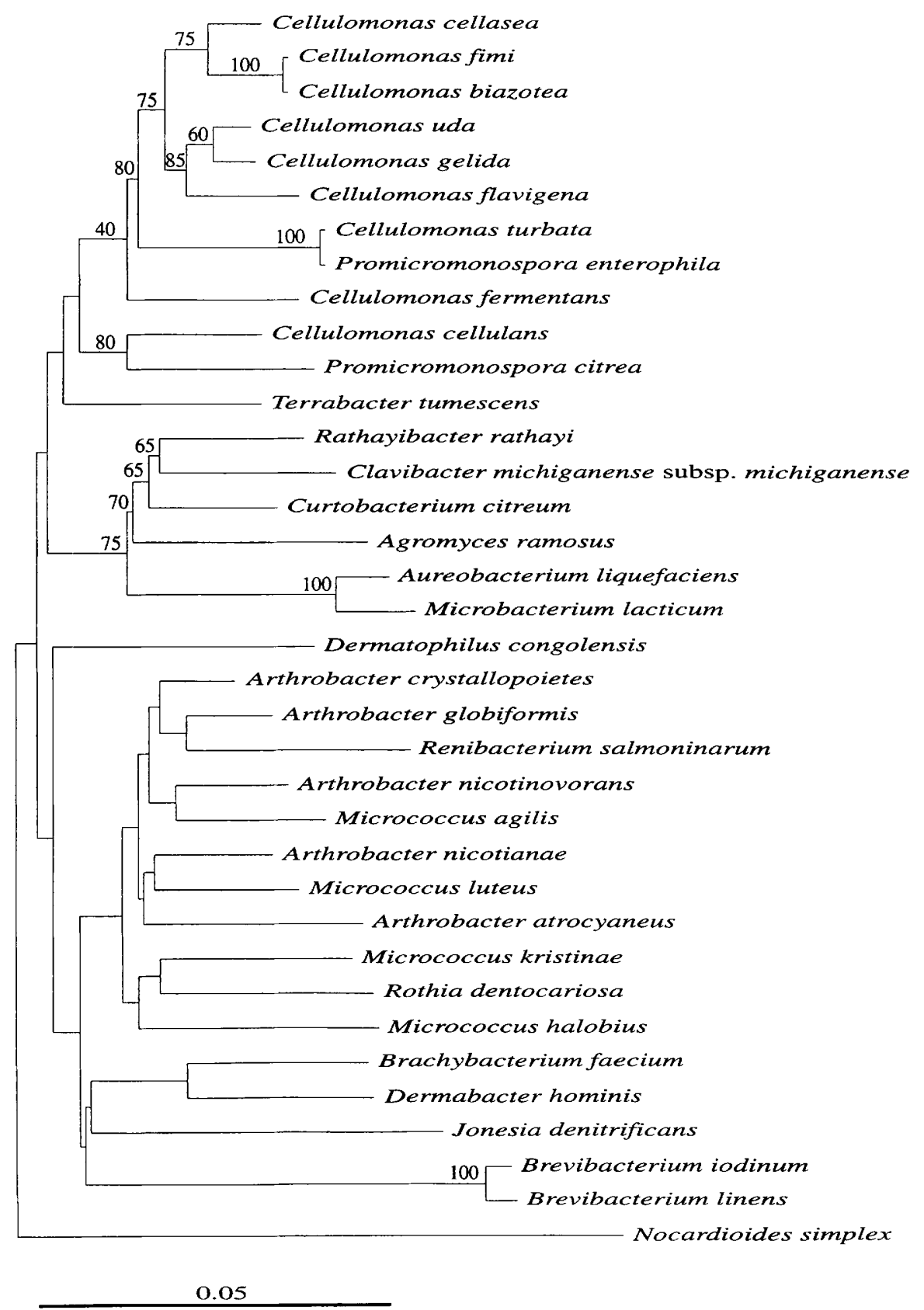

FIG. 1. Distance matrix tree (3) showing the relationships of members of the Arthrobacter lineage in the subphylum containing the order Actinomycetales. The corrected dissimilarity values for members of the family Cellulomonadaceae and two reference organisms are shown in Table 1. Values for the other organisms have been published previously $(11,12,17)$. The values indicate the percentages of occurrence in 300 bootstrapped trees; only values that are greater than $40 \%$ are shown. Bar $=5$ nucleotide substitutions per 100 nucleotides.

members of this lineage from about 10 to about $50(1,11,12$, 17) allows much more precise measurement of relationships, a specific relationship between Dermabacter hominis and members of the Arthrobacter-Micrococcus group cannot be confirmed by results of this study.

Intrafamily relationships. When measured by the levels of similarity of the $16 \mathrm{~S}$ rDNAs of the most unrelated members, the phylogenetic depth of the family Cellulomonadaceae is as great as the depth that separates the five genera that belong to the Microbacteriaceae and the four genera in the ArthrobacterMicrococcus group. In these taxa, the traditionally defined gen- era are not always clearly separated by a combination of phenotypic and chemotaxonomic properties, and their taxonomy is presently under revision $(11,17)$. Except for confirmation of the intermixing of Cellulomonas and Oerskovia species (22), the intrafamily relationships of the members of the Cellulomonadaceae which we observed were not expected. While in a previous phylogenetic analysis of members of the genera Cellulomonas and Promicromonospora based on the partial 16S rRNA sequences of five species, workers found that $P$. citrea groups outside the radiation of Cellulomonas species, the situation is different when almost all species of the genera $\mathrm{Cel}$ - 
lulomonas and Promicromonospora are included. Type species $P$. citrea clusters with Cellulomonas cellulans, while $P$. enterophila is highly related to Cellulomonas turbata (level of sequence similarity, 99.4\%). The close relationship between the latter two species has been noted previously (27), and DNA-DNA reassociation experiments will be required to determine whether these two taxa should be combined. Differences between members of the Cellulomonas-Oerskovia group and Promicromonospora species are mainly phenotypic. Unlike cellulomonads, Cellulomonas (Oerskovia) turbata and Promicromonospora species do not form branched rods but produce persistent or transient branching mycelia which fragment in older cultures. Promicromonospora species produce aerial mycelia (which have never been detected in Cellulomonas [Oerskovia] turbata), form motile elements, and are strictly aerobic $(15,27)$.

Unexpectedly, T. tumescens appears to share ancestry with the cellulomonads. In previous reports $(4,14)$, workers found that this species branched more deeply and close to the root of the Arthrobacter lineage. The difference between these reports and our findings may be due to the lengths of the $16 \mathrm{~S}$ rDNA sequences compared. All previous investigations were based on a data set in which the $3^{\prime}$-terminal 200 nucleotides of the sequence were missing, while the data sets compared in this study included about $98 \%$ of the complete sequence.

Intrageneric structure of the genus Cellulomonas. The relationship among certain Cellulomonas species determined by 16S rDNA analysis is in good agreement with the results of DNA-DNA reassociation studies $(22,23)$. The species pair Cellulomonas biazotea and Cellulomonas fimi and the species pair Cellulomonas gelida and Cellulomonas uda exhibit high levels of $16 \mathrm{~S}$ rDNA similarity (99.7 and $98.8 \%$, respectively) and have significant phylogenetic relationships, as indicated by bootstrap values of 100 and $60 \%$, respectively, and the corresponding levels of DNA similarity are high (55 and 45\%, respectively). Cellulomonas flavigena and Cellulomonas cellasea are closely related to the Cellulomonas gelida-Cellulomonas $u d a$ group (bootstrap value, $85 \%$ ) and the Cellulomonas biazotea-Cellulomonas fimi group (bootstrap value, $100 \%$ ), respectively. Cellulomonas cellulans appears to be the most divergent species in the genus, as judged by the binary levels of 16S rDNA similarity with other Cellulomonas species (levels of similarity, 93.8 to $95.4 \%$ ) and by its phylogenetic position. Fine-tuning of intrageneric relationships is not possible on the basis of low levels of DNA-DNA similarity (i.e., levels of similarity between 20 and $35 \%)(22,23)$, and direct correlations between DNA reassociation values and $16 \mathrm{~S}$ rDNA similarity values cannot be made. Phylogenetic separation of Cellulomonas cellulans from the other Cellulomonas species is consistent with differences in the amino acid compositions of the peptidoglycans of these organisms. Cellulomonas cellulans, which encompasses strains formerly classified as Oerskovia xanthineolytica, Nocardia cellulans, Brevibacterium fermentans, Corynebacterium manihot, and Arthrobacter luteus, has type A $4 \alpha$ peptidoglycan (L-Lys-D-Ser-D-Asp), while all other Cellulomonas species have type A4 $\beta$ peptidoglycan (L-Orn-D-Asp or L-OrnD-Glu). Comparative analyses of the chemotaxonomic and phenotypic properties of all members of the Cellulomonas group are needed for a future revision of the taxonomy of these organisms.

\section{REFERENCES}

1. Cai, J., and M. D. Collins. 1994. Phylogenetic analysis of species of the meso-diaminopimelic acid-containing genera Brevibacterium and Dermabacter. Int. J. Syst. Bacteriol. 44:583-585.

2. Collins, M. D., J. Brown, and D. Jones. 1988. Brachybacterium faecium gen. nov., sp. nov., a coryneform bacterium from poultry deep litter. Int. J. Syst.
Bacteriol. 38:45-48.

3. De Soete, G. 1983. A least squares algorithm for fitting additive trees to proximity data. Psychometrica 48:621-626.

4. Embley, T. M., and E. Stackebrandt. 1994. The molecular phylogeny and systematics of the actinomycetes. Annu. Rev. Microbiol. 48:257-289.

5. Fiedler, F., and O. Kandler. 1973. Die Mureintypen in der Gattung Cellulomonas Bergey et al. Arch. Mikrobiol. 89:41-50.

6. Fiedler, F., J. Seger, A. Schrettenbrunner, and H. P. R. Seeliger. 1984. The biochemistry of murein and cell wall teichoic acids in the genus Listeria. Syst. Appl. Microbiol. 5:360-376.

7. Jones, D. 1975 . A numerical taxonomic study of coryneform and related bacteria. J. Gen. Microbiol. 87:360-376.

8. Jones, D., and M. D. Collins. 1986. Irregular, non-sporing gram-positive rods, p. 1261-1266. In P. H. A. Sneath, N. S. Mair, M. E. Sharpe, and J. G. Holt (ed.), Bergey's manual of systematic bacteriology, vol. 2. Williams and Wilkins, Baltimore.

9. Jones, D., and M. D. Collins. 1988. Taxonomic studies on some human cutaneous coryneform bacteria: description of Dermabacter hominis gen. nov., spec. nov. FEMS Microbiol. Lett. 51:51-56.

10. Jukes, T. H., and C. R. Cantor. 1969. Evolution of protein molecules, p. 21-132. In H. N. Munro (ed.), Mammalian protein metabolism. Academic Press, New York.

11. Koch, C., F. A. Rainey, and E. Stackebrandt. 1994. 16S rDNA studies on members of Arthrobacter and Micrococcus: an aid for their future taxonomic restructuring. FEMS Microbiol. Lett. 123:167-172.

12. Koch, C., P. Schumann, and E. Stackebrandt. 1995. Reclassification of Micrococcus agilis (Ali-Cohen 1889) to the genus Arthrobacter as Arthrobacter agilis comb. nov. and emendation of the genus Arthrobacter. Int. J. Syst. Bacteriol. 45:837-839.

13. Lapage, S. P., P. H. A. Sneath, E. F. Lessel, V. B. D. Skerman, H. P. R. Seeliger, and W. A. Clark (ed.). 1992. International code of nomenclature of bacteria. 1990 revision. American Society for Microbiology, Washington, D.C.

14. Larsen, N., G. J. Olsen, B. L. Maidak, M. McCaughey, J. R. Overbeek, T. J. Macke, T. L. Marsh, and C. R. Woese. 1993. The Ribosomal Database Project. Nucleic Acids Res. 21:3021-3023.

15. Prauser, H., M. P. Lechevalier, and H. Lechevalier. 1970. Description of Oerskovia gen. n. to harbor Ørskov's motile Nocardia. Appl. Microbiol. 19:534.

16. Rainey, F. A., M. Dorsch, H. W. Morgan, and E. Stackebrandt. 1992. 16S rDNA analysis of Spirochaeta thermophila: its phylogenetic position and implications for the systematics of the order Spirochaetales. Syst. Appl. Microbiol. 15:197-202.

17. Rainey, F. A., N. Weiss, H. Prauser, and E. Stackebrandt. 1994. Further evidence for the phylogenetic coherence of actinomycetes with Group Bpeptidoglycan and evidence for the phylogenetic intermixing of the genera Microbacterium and Aureobacterium as determined by $16 \mathrm{~S}$ rDNA analysis. FEMS Microbiol. Lett. 118:135-140.

18. Rocourt, J., U. Wehmeyer, and E. Stackebrandt. 1987. Transfer of Listeria denitrificans to a new genus, Jonesia gen. nov., as Jonesia denitrificans comb. nov. Int. J. Syst. Bacteriol. 37:266-270.

19. Saitou, N., and M. Nei. 1987. The neighbor-joining method: a new method for reconstructing phylogenetic trees. Mol. Biol. Evol. 4:406-425.

20. Schleifer, K. H., and O. Kandler. 1972. Peptidoglycan types of bacterial cell walls and their taxonomic implications. Bacteriol. Rev. 36:407-477.

21. Stackebrandt, E., F. Fiedler, and O. Kandler. 1978. Peptidoglycan type and cell wall polysaccharide composition of Cellulomonas cartalyticum and some coryneform organisms. Arch. Microbiol. 117:115-118.

22. Stackebrandt, E., M. Häringer, and K.-H. Schleifer. 1980. Molecular genetic evidence for the transfer of Oerskovia species into the genus Cellulomonas. Arch. Microbiol. 127:179-185.

23. Stackebrandt, E., and O. Kandler. 1979. Taxonomy of the genus Cellulomonas, based on phenotypic characters and deoxyribonucleic acid-deoxyribonucleic acid homology, and proposal of seven neotype strains. Int. J. Syst. Bacteriol. 29:273-282.

24. Stackebrandt, E., B. J. Lewis, and C. R. Woese. 1980. The phylogenetic structure of the coryneform group of bacteria. Zentralbl. Bakteriol. Parasitenkd. Infektionskr. Hyg. Abt. 1 Orig. Reihe C 1:137-149.

25. Stackebrandt, E., W. Ludwig, E. Seewaldt, and K.-H. Schleifer. 1983. Phylogeny of sporeforming members of the order Actinomycetales. Int. J. Syst. Bacteriol. 33:173-180.

26. Stackebrandt, E., and H. Prauser. 1991. Assignment of the genera Cellulomonas, Oerskovia, Promicromonospora and Jonesia into Cellulomonadaceae fam. nov. Syst. Appl. Microbiol. 14:261-265.

27. Stackebrandt, E., and H. Prauser. 1991. The family Cellulomonadaceae, p. 1323-1345. In A. Balows, H. G. Trüper, M. Dworkin, W. Harder, and K.-H. Schleifer (ed.), The prokaryotes. Springer Verlag, New York.

28. Stackebrandt, E., H. Seiler, and K.-H. Schleifer, 1992. Union of the genera Cellulomonas Bergey et al. and Oerskovia Prauser et al. in a redefined genus Cellulomonas. Zentralbl. Bakteriol. Parasitenkd. Infektionskr. Hyg. Abt. 1 Orig. Reihe C 2:401-409. 